\title{
"Blue bodies" in a case of cryptogenic fibrosing alveolitis (desquamative type) - an ultra-structural study
}

\author{
I T GARDINER AND J S UFF \\ From the Departments of Medicine and Histopathology, Royal Postgraduate Medical School, \\ Hammersmith Hospital, London W12 OHS, UK
}

Gardiner, I T, and Uff, J S (1978). Thorax, 33, 806-813. "Blue bodies" in a case of cryptogenic fibrosing alveolitis (desquamative type) - an ultra-structural study. A patient with cryptogenic fibrosing alveolitis, with both mural and desquamative features, had two lung biopsies at the times of coronary artery surgery. These lung specimens were studied, using light and electron microscopy, with immunofluorescence techniques and electron microanalysis. In addition to the typical changes of cryptogenic fibrosing alveolitis previously reported, we found "blue-staining bodies" within alveolar macrophages and giant cells. These bodies were 15-25 $\mu \mathrm{m}$ in diameter with an iron rich outer rim and core of connective tissue mucin-possibly chondroitin sulphate or dermatan sulphate. It seems unlikely that these "blue bodies" were due to fibreglass dust to which the patient had had a trivial exposure, but their exact nature and significance remains unclear.

Since Liebow et al (1965) first described desquamative interstitial pneumonitis, there have been several studies reporting the ultra-structural characteristics of both biopsy and necropsy specimens (Brewer et al, 1969; Shortland et al, 1969; Farr et al, 1970; Patchefsky et al, 1971). While these authors have described in detail many features of the intra-alveolar cells, including intranuclear inclusion bodies, there have been no previous reports of intracytoplasmic inclusion bodies ("blue bodies").

\section{Case history}

A 55-year-old man was referred to hospital in 1974 for coronary artery surgery. He had a sixmonth history of exertional dyspnoea but no cough or sputum, despite having smoked 15 cigarettes a day for 35 years. He had worked as a bus driver for most of his life, turning to clerical work only when disabled by angina. As a clerk he had trivial and infrequent exposure to fibreglass and resin dust. For about 20 minutes each working day over a three-year-period he walked through workshops where mock-ups of aircraft components were being manufactured from fibreglass. The atmosphere in these rooms was not obviously dusty, and extractor fans were in constant use. The materials used were epoxy resin, polyester resin, and amine hardeners.

Inquiry at the plant did not show any respiratory effects from these materials in other workers. The patient had no exposure to fungi or pet birds; avian and fungal precipitins and rheumatoid factor were not found in the patient's serum. His chest radiograph had previously been regarded as normal, but a review of his films since 1970 showed a fine granular appearance in the lower zones. This appearance has remained unchanged. Because of some suspicion of lung abnormality, a wedge biopsy of the right upper lobe was performed at the time of his first coronary artery graft early in 1974. On the results of this biopsy, he was given an eight-week course of prednisolone without objective improvement in his condition. This treatment was curtailed by the need for further coronary artery surgery, which was unsuccessful, and a third operation was performed in 1975 when another lung specimen was taken from the right upper lobe. No further treatment for his pulmonary condition has been offered since then, and there have been minimal changes in his lung 
function tests (table). He is quite disabled by angina.

\section{Methods}

Sections of paraffin embedded material from both biopsy specimens were stained as appropriate with haematoxylin and eosin, Weigert's impregnation for elastin (counterstained with van Gieson's stain), periodic acid Schiff after diastase digestion, von Kossa's and Perls's stains, alizarin red $\mathbf{S}$, and Alcian blue. Sections of the first specimen were stained by the immunoperoxidase method of Taylor and Burns (1974). Frozen material from the second specimen was examined by direct immunofluorescence (Dakopatts A/S, Copenhagen, Denmark) and further tissue was fixed in glutaraldehyde, post-fixed in Osmium tetroxide, and embedded in resin. The sections were examined by electron microscopy and by electronprobe microanalysis.

\section{Results}

The first lung specimen showed the characteristic appearance of cryptogenic fibrosing alveolitis, with infiltration of the septa by inflammatory cells and the accumulation of macrophages and giant cells in the alveolar spaces. There was a moderate amount of interstitial fibrosis but no evidence of honeycombing (fig 1). The lesions showed no centrilobular accentuation, and there was no evidence of bronchiolitis, vasculitis, or necrosis. Granulomas were not seen.

A striking feature was the presence of numerous inclusions (which we called blue bodies) in alveolar spaces (fig 2). The majority were within giant cells and macrophages, but some appeared to be lying free. They measured $15-25 \mu \mathrm{m}$ in diameter, and consisted of a central round or oval core surrounded by a clear space, with an outer rim of granular brown material, often with a crescentic outline. The core stained blue with haematoxylin and eosin and with Alcian blue, and the rim was strongly positive with Perls's, Alcian blue, and von Kossas' stains, but negative with alizarin red $\mathbf{S}$. Formalin-fixed material from the second biopsy specimen was almost normal, but glutaraldehydefixed material showed the same changes as the first. Electron microscopy of this confirmed that nearly all the cells in the alveolar spaces were macrophages.

The blue bodies had a characteristic appearance on electron microscopy. The core was composed of radially arranged fine fibrillary material, surrounded by a clear zone, while the rim showed numerous small electron dense granules, which were also present in some cores. These structures were not membrane-bound (figs 3 and 4). Although some of the blue bodies appeared to be lying free in alveolar spaces on light microscopy, they were all intracytoplasmic on electron microscopy, and most were in giant cells. On electron microanalysis the rim contained only iron. In blue bodies with fine granules in the core, small amounts of iron were also detected, but otherwise they were negative. Occasionally a second type of giant cell inclusion was seen. These were much less frequent and smaller in size. They were composed of a core of small, irregular, round, electron dense structures, surrounded by a rim of numerous dark granules. Electron microanalysis showed that the core often contained silicon and arsenic, and that the rim was rich in iron. Electron microanalysis also showed that the cytoplasm of macrophages contained dispersed iron granules. Results of immunofluorescence and immunoperoxidase studies were negative.

\section{Discussion}

Light and electron microscopy confirmed that this patient has fibrosing alveolitis with desquamative and mural features, the former predominating.

Table Lung function tests

\begin{tabular}{|c|c|c|c|c|c|c|}
\hline & $\begin{array}{l}\text { December } \\
1974\end{array}$ & $\begin{array}{l}\text { June } \\
1975\end{array}$ & $\begin{array}{l}\text { August } \\
1975\end{array}$ & $\begin{array}{l}\text { March } \\
1976\end{array}$ & $\begin{array}{l}\text { January } \\
1977\end{array}$ & $\begin{array}{l}\text { Predicted } \\
\text { normal } \\
\text { values }\end{array}$ \\
\hline $\begin{array}{l}\text { Forced expiratory volume } \\
\text { (1 s) (1) } \\
\text { Vital capacity (l) } \\
\text { Transfer coefficient } \\
\text { (mmol/min/kPa/l) } \\
\text { Total lung capacity (l) } \\
\text { Residual volume (l) }\end{array}$ & $\begin{array}{l}2 \cdot 1 \\
2 \cdot 6 \\
1 \cdot 01 \\
4 \cdot 15 \\
1 \cdot 50\end{array}$ & $\begin{array}{l}2 \cdot 15 \\
2 \cdot 60 \\
\\
0 \cdot 98 \\
4 \cdot 8 \\
1 \cdot 7\end{array}$ & $\begin{array}{l}2 \cdot 30 \\
2 \cdot 75 \\
\\
0 \cdot 94 \\
5 \cdot 1 \\
2 \cdot 1\end{array}$ & $\begin{array}{l}2 \cdot 10 \\
2 \cdot 60 \\
\\
1 \cdot 11 \\
4 \cdot 3 \\
1 \cdot 50\end{array}$ & $\begin{array}{l}2 \cdot 2 \\
2 \cdot 4 \\
\\
0 \cdot 86 \\
5 \cdot 2 \\
2 \cdot 2\end{array}$ & $\begin{array}{l}2 \cdot 6-3 \cdot 6 \\
3 \cdot 4-4 \cdot 6 \\
1 \cdot 2-1 \cdot 7 \\
5 \cdot 3-7 \cdot 1\end{array}$ \\
\hline
\end{tabular}

Blood gases (1974): at rest; breathing air $-\mathrm{PaO}_{2}=11 \cdot 8 \mathrm{kPa} ; \mathrm{PaCO}_{2}=5 \cdot 2 \mathrm{kPa} ; \mathrm{pH}=7 \cdot 43$. 


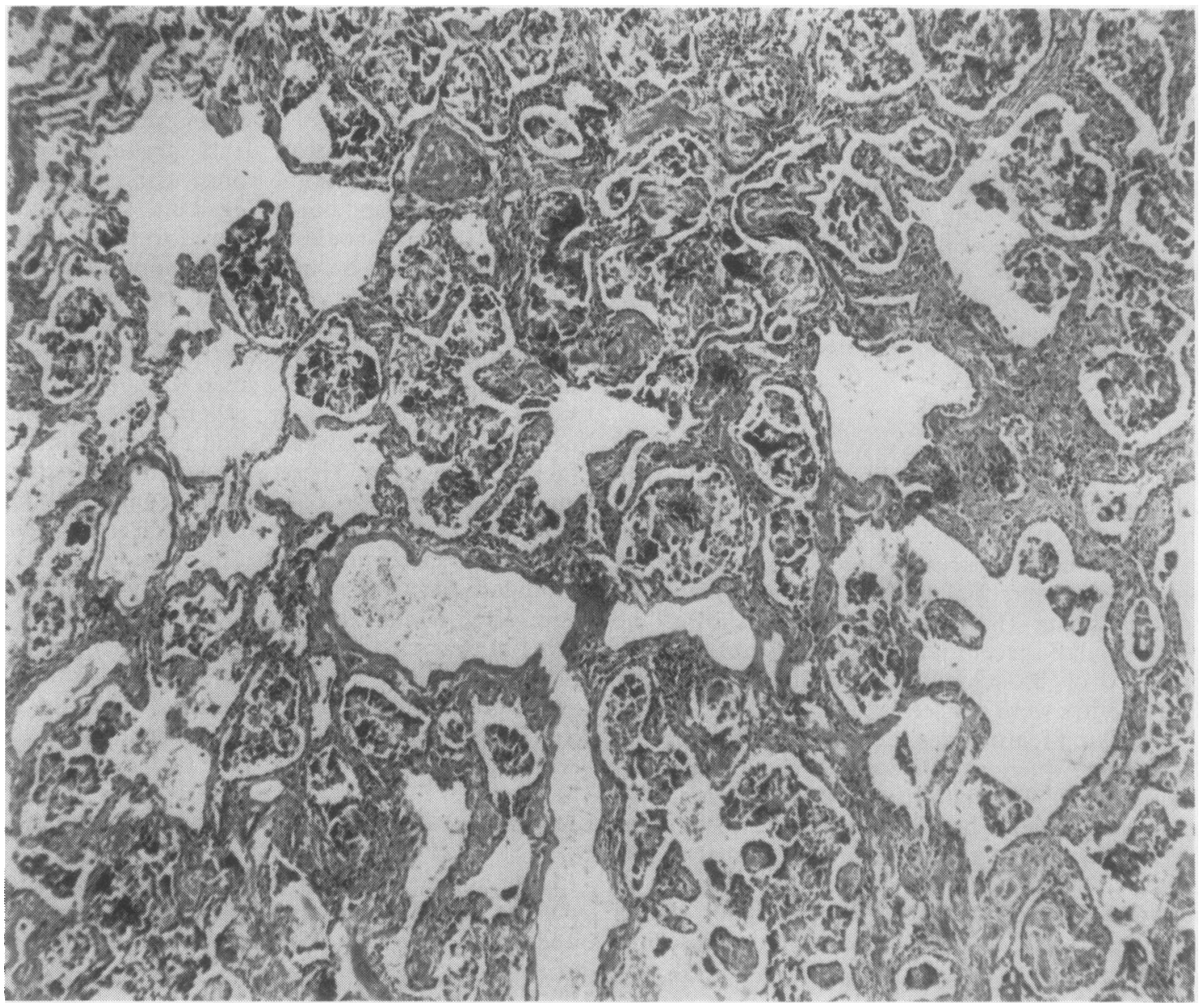

Fig 1 Low power photomicrograph showing thickening of alveolar septa with mild interstial fibrosis and numerous collections of macrophages and giant cells in alveolar spaces (Haematoxylin and eosin $\times 60$ ). 


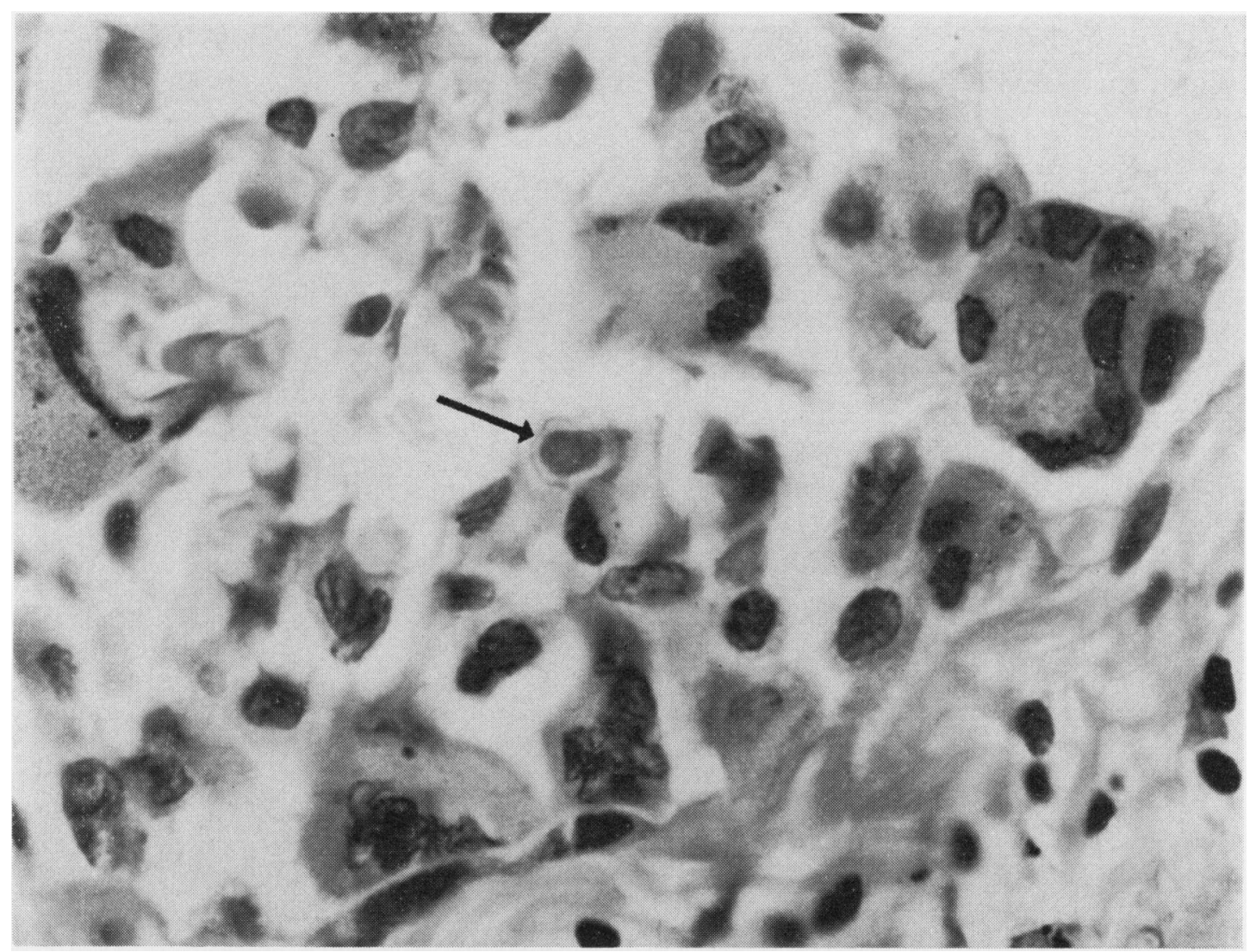

Fig 2 A blue body (arrowed) lying free in an alveolar space. Surrounding it are numerous alveolar macrophages $(H \& E \times 1500)$. 


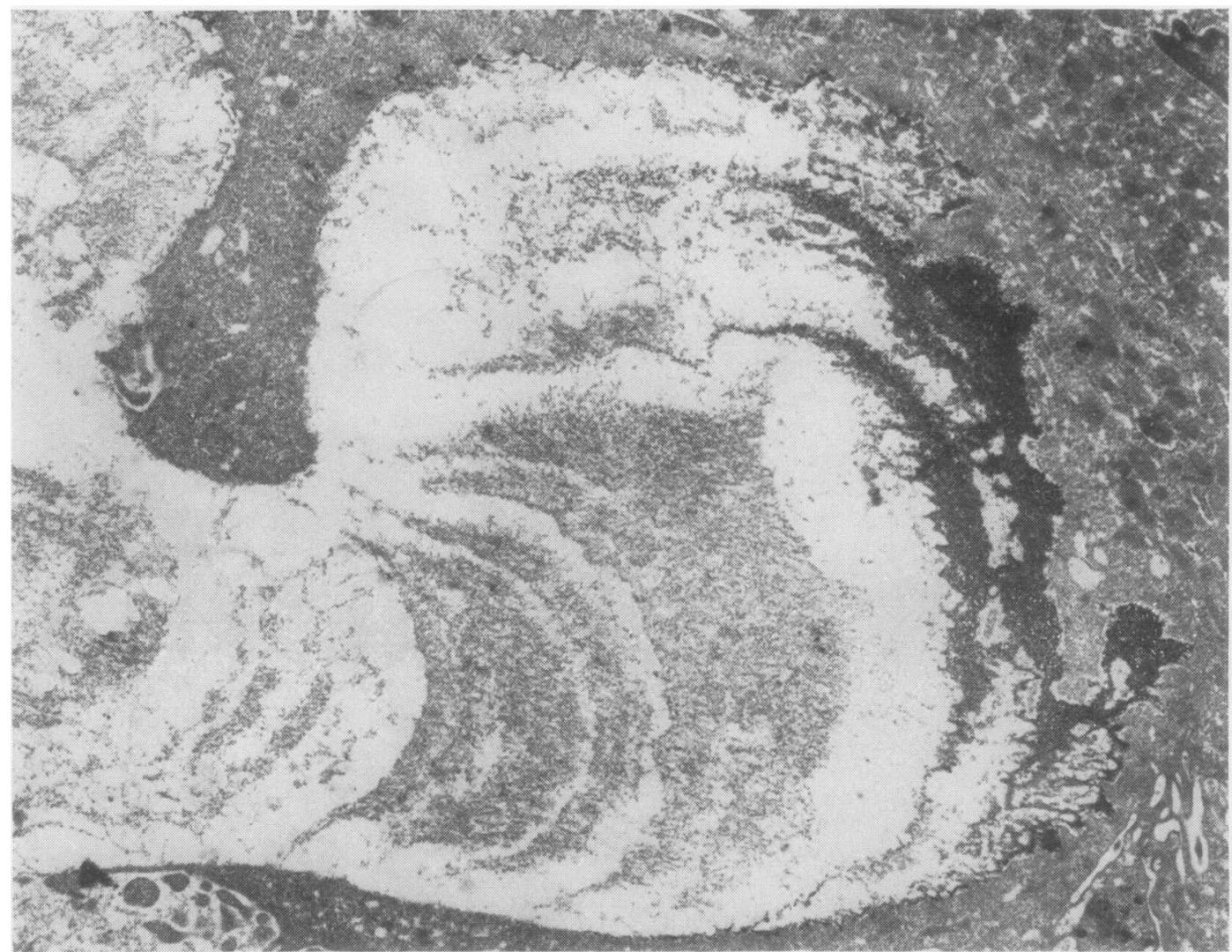

Fig 3 A blue body within a macrophage. Granular electron dense crescentic rim and laminated core material can be seen $($ Electron micrograph $\times 8000)$. 


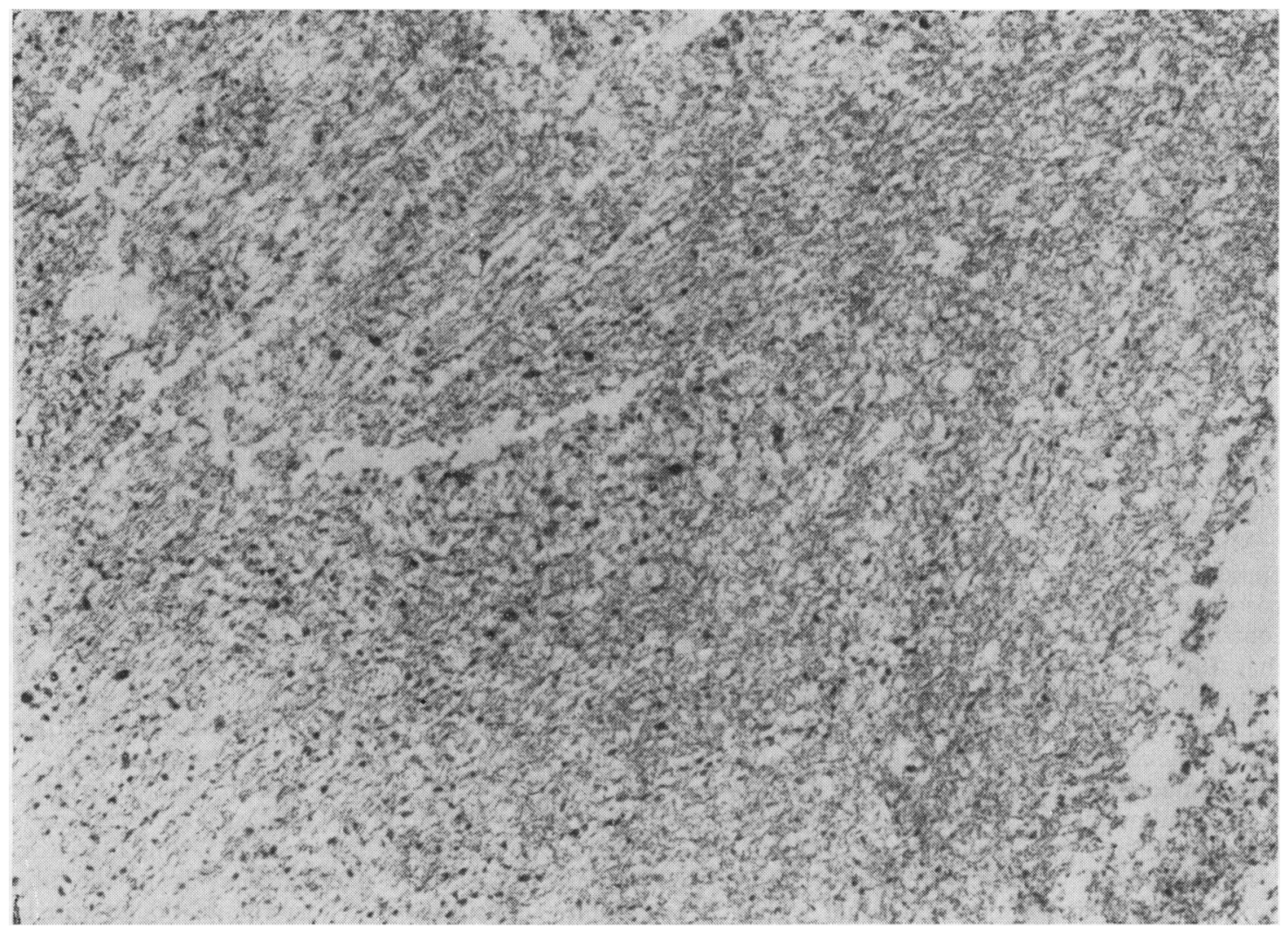

Fig 4 Fibrillary appearance of core. Some electron dense granules are also seen (Electron micrograph $\times 20000$ ). 
Practically all the free alveolar cells were macrophages with very few type II pneumocytes, a finding in accord with others (Brewer et al, 1969; Farr et al, 1970). Apart from containing the blue bodies, these macrophages did not show any previously reported abnormalities (Rhodes, 1973). It was initially thought that the blue bodies might be formed from inhaled fibreglass particles (Davis, 1964). Gross et al (1970) have shown that hamsters (but not rats) exposed to high concentrations of fibreglass dust for two years develop calcific alveolar microliths amid small collections of dust-laden macrophages. Gross et al (1971b) examined the lungs of both city dwellers and fibreglass factory workers and found small, round non-fibrous ferruginous bodies with a sharp outer black layer of variable thickness in all cases. In an animal study Schepers et al (1958) found fibreglass resin dust (fibreglass resin reinforced calcium carbonatefilled polyester resin) to be non-toxic. Guinea pigs developed intra-alveolar macrophages and giant cells, which regressed spontaneously despite continuing exposure to the fibreglass dust. These cells had no influence on adjacent alveolar walls and no new collagen was laid down in them. No radiological or pathological change has yet been found in the lungs of people heavily exposed to fibreglass dust (Hill et al, 1973; American College of Physicians, 1976).

Michaels (1967) has seen bodies similar to blue bodies in the lungs of woodworkers. He described basophilic, roughly circular particles with concentric laminations, and special stains suggested that the cores were wood dust. Some were engulfed by histiocytes or giant cells and were seen within the lumen of bronchioles. Others were seen in the thickened walls of alveoli and alveolar ducts surrounded by fibroblasts, and it was thought probable that they were ultimately responsible for the areas of peribronchiolar fibrosis seen.

It is unlikely, however, that blue bodies are formed from inhaled material. Blue bodies were seen in large numbers in routinely prepared histological sections, while ferruginous bodies are usually shown only after tissue digestion and centrifugation. Gross et al (1971a) reported that feruginous bodies "are not likely to be encountered or recognised in routine lung sections except rarely." The same is true for other dust particles. Also the distribution of blue bodies in the lung specimens was not uniform, and they were found only within the cytoplasm of intra-alveolar cells. The morphology of blue bodies was different from that of both ferruginous bodies (Gross et al, 1971a) and asbestos bodies (Davies, 1964). Electron microscopy and electron probe microanalysis showed the distinction between blue bodies and inhaled dust particles particularly clearly (Berry et al, 1976).

Although blue bodies are probably not formed $\stackrel{\mathbb{D}}{\Omega}$ from inhaled dust particles, the second type of in- क clusion may be. The appearance and distribution $\overrightarrow{0}$ of these inclusions are compatible with those of mineral dust particles. They also contain silicon $\vec{\omega}$ and arsenic. We wondered if fibreglass was the source for these inclusions as arsenic may be $\vec{x}$ added to glass during manufacture to remove iron impurities. However, the patient had had only a $\%$ trivial occupational exposure. It is impossible to tell whether these particles are the cause of his

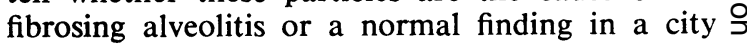
dweller.

The electron probe study of the remainder of

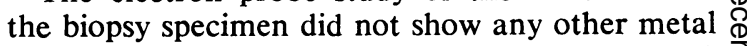
(in particular, cobalt, chrome, nickel, or tungsten) which had been linked with lung fibrosis by others $\stackrel{\Phi}{\longrightarrow}$ using this technique (Siegesmund et al, 1974). $\vec{\varphi}$ Moreover we felt an immune process was unlikely to be the cause of the blue bodies as, like Dill et al (1975), we found no evidence of immunoglobulins or complement deposition in the lung tissue. Alcian blue staining of the core of the blue bodies suggests the presence of a connective tissue mucin-possibly chondroitin sulphate or dermatan sulphate. (It is noteworthy that Motomiya et al $\overline{\vec{O}}$ (1975) found dermatan sulphate to be increased 3 from the normal $5 \%$ to $16 \%$ in the lung in fibrosing alveolitis.) Furthermore, electron microscopy of the core shows a fibrillary pattern consistent with a glycosaminoglycan. The presence of iron (and not calcium) in the outer rim is responsible for the positive von Kossa's stain and suggests that these bodies have been present for some time.

We think that blue bodies are related in some way to the inflammatory process. Giant cell inclusions can sometimes be seen in other inflammatory diseases, but these are different from the blue $\frac{D}{0}$ bodies described here. Schaumann bodies can be seen in giant cells in sarcoidosis and less often in $\tilde{O}$ other granulomatous diseases. Blue bodies differ from Schaumann bodies in their light micro- $N$ scopic appearances, special staining characteristics $\omega$ (Jones Williams, 1960), and electron microscopic appearances (Dumont and Sheldon, 1965). Judd et al (1975) described lucent crystalline inclusions $\underset{\oplus}{\mathbb{D}}$ in a case of sarcoidosis, which were similar to blue bodies at the electron microscopic level. These inclusions were distinct from Schaumann

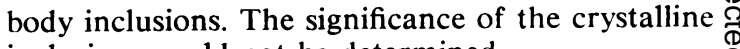
inclusions could not be determined.

Liebow (personal communication) has seen similar blue bodies in other cases of interstitial 8 
pneumonitis without a history of occupational dust exposure. He believed these blue bodies to be indicative of late disease and that they represent residual bodies. We found that on electron microscopy blue bodies had a unique appearance and were distinct from residual bodies. The core of the blue body may represent indigestible, phagocytosed material, although the giant cells appeared to have normal lysozomes. A more likely suggestion is the overproduction or failure of secretion of some macrophage product. It is known that macrophages are secretory cells (Carr and Norris, 1977), and James and Jones Williams (1974) have shown that the epithelioid cells of sarcoid have vacuoles containing mucoglycoprotein. The presence of blue bodies in fibrosing alveolitis may indicate a difference between alveolar macrophages and macrophages of other sites.

We are grateful to Dr C Oakley, Dr A Buchanan, and Dr N B Pride for allowing us to study their patient. We are also grateful to Professor W M Thurlbeck, Professor H K Weinbren, Dr B E Heard, and Dr D Landon for their helpful advice.

\section{References}

American College of Chest Physicians, Committee on Environmental Health (1976). Pulmonary response to fiberglass dust. Chest, 69, 216-219.

Berry, J P, Henoc, P, Galle, P, and Pariente, R (1976). Pulmonary mineral dust: a study of ninety patients by electron microscopy, electron microanalysis and electron microdiffraction. American Journal of Pathology, 83, 427-456.

Brewer, D B, Heath, D, and Asquith, P (1969). Electron microscopy of desquamative interstitial pneumonia. Journal of Pathology and Bacteriology, 97, 317-323.

Carr, I, and Norris, P (1977). The fine structure of human macrophage granules in sarcoidosis. Journal of Pathology, 122, 29-33.

Davis, J M G (1964). The ultrastructure of asbestos bodies from guinea-pig lungs. British Journal of Experimental Pathology, 45, 634-646.

Dill, J, Ghose, T, and Landrigan, P (1975). Cryptogenic fibrosing alveolitis. Chest, 67, 411-416.

Dumont, A, and Sheldon, H (1965). Changes in fine structure of macrophages in experimentally produced tuberculous granulomas in hamsters. Laboratory Investigation, 14, 2034-2055.

Farr, G H, Horley, R A, and Hennigar, G R (1970). Desquamative interstitial pneumonia-an electron microscopic study. American Journal of Pathology, 60, 347-370.

Gross, P, Kaschak, M, Tolker, E B, Babyak, M A, and de Treville, R T P (1970). The pulmonary reaction to high concentration of fiber glass dust. Archives of Environmental Health, 20, 696-704.
Gross, P, Tuma, J, and de Treville, R T P (1971a). Unusual ferruginous bodies: their formation from non-fibrous particulates and from carbonaceous fibrous particles. Archives of Environmental Health, 22, 534-537.

Gross, P, Tuma, J, and de Treville, R T P (1971b). Lungs of workers exposed to fiber glass-a study of their pathological changes and their dust content. Archives of Environmental Health, 23, 67-76.

Hill, J W, Whitehead, W S, Cameron, J D, and Hedgecock, G A (1973). Glass fibres: absence of pulmonary hazard in production workers. British Journal of Industrial Medicine, 30, 174-179.

James, E M V, and Jones Williams, W (1974). Fine structure and histochemistry of epithelioid cells in sarcoidosis. Thorax, 29, 115-120.

Jones Williams, W (1960). The nature and origin of Schaumann bodies. Journal of Pathology and Bacteriology, 79, 193-201.

Judd, P A, Finnegan, P, and Curran, R C (1975). Pulmonary sarcoidosis: a clinico-pathological study. Journal of Pathology, 115, 191-198.

Liebow, A A, Steer, A, and Billingsley, J G (1965). Desquamative interstitial pneumonia. American Journal of Medicine, 39, 369-404.

Michaels, L (1967). Lung changes in woodworkers. Canadian Medical Association Journal, 96, 11501155.

Motomiya, M, Arai, H, Sato, H, Yokosawa, A, Nagai, $H$, and Konno, $K$ (1975). Increase in dermatan sulphate in a case of pulmonary fibrosis. Tohoku Journal of Experimental Medicine, 115, 361-365.

Patchefsky, A S, Banner, M, and Freundlich, I M (1971). Desquamative interstitial pneumonia. Significance of intranuclear vessel-like inclusion bodies. Annals of Internal Medicine, 74, 322-327.

Rhodes, M L (1973). Desquamative interstitial pneumonia-new ultra-structural findings. American Review of Respiratory Disease, 108, 950-954.

Schepers, G W H, Durkan, T M, Delahant, A B, Redlin, A, Schmidt, J G, Creedon, F T, Jacobson, J W, and Bailey, D A (1958). Biological action of fibre glass-plastic dust. Archives of Industrial Health, 18, 34-57.

Siegesmund, K A, Funahashi, A, and Pinter, K (1974). Identification of metals in lung from a patient with interstitial pneumonia. Archives of Environmental Health, 28, 345-349.

Shortland, J R, Darke, C S, and Crane, H J (1969). Electron microscopy of desquamative interstitial pneumonia. Thorax, 24, 192-208.

Taylor, C R and Burns, J (1974). The demonstration of plasma cells and other immunoglobulin containing cells in formalin-fixed paraffin-embedded tissues using peroxidase-labelled antibody. Journal of Clinical Pathology, 27, 14-20.

Requests for reprints to: Dr J S Uff, Department of Histopathology, Royal Postgraduate Medical School, Hammersmith Hospital, Du Cane Road, London W12 0HS. 